\title{
DOBRAS DE UMA ORIGEM: CLÍNICA, CRIAÇÃO E UTOPIA
}

\author{
$*$ \\ Ariane Santellano de Freitas \\ Universidade Federal do Rio Grande do Sul - UFRGS - Brasil \\ Edson Luiz André Sousa \\ Universidade Federal do Rio Grande do Sul - UFRGS - Brasil
}

\section{Resumo}

Este trabalho trata de uma escrita acerca do ato criativo e seus desdobramentos naquilo que toca à clínica psicanalítica. $\mathrm{O}$ diálogo entre arte e psicanálise se mostra potente na medida em que esses campos se aproximam do mesmo modo que se estranham, causando dúvidas e reflexões que culminam na possibilidade da criação de novas formas, novos caminhos. Partimos de uma cena clínica em que o gesto de criação encontra possibilidade analítica na medida em que esse ato é vivido no contexto da transferência, onde o olhar do outro ocupa lugar essencial. A reflexão sobre o caso clínico procura aprofundar eixos de reflexão como a formação da imagem, as interfaces entre significante e inconsciente e ato analítico e utopia.

Palavras-Chave: Ato Criativo. Psicanálise. Utopia.

"O problema é não como findar uma dobra, mas como continua-la, fazê-la atravessar o teto, leva-la ao infinito.”

Gilles Deleuze.

\section{Dobras de um Caso Clínico ${ }^{1}$}

Amadeo chegou à sala de atendimento trazendo nas mãos uma dobradura. Mostrou à terapeuta, abrindo todo o papel para que ela visse as marcas que haviam sido feitas, podendo

\footnotetext{
${ }^{1}$ Os nomes foram alterados a fim de garantir o sigilo do caso.
} 
identificar como se chegou àquela forma. Pediu-lhe para que se repetisse o feitio em outro papel, seguindo o caminho que as marcas da dobradura já feita apontavam. Criaram-se assim, vários outros objetos de papel, iguais ao que ele trouxera, ao longo de toda aquela sessão, onde a necessidade de produção de duplos se fez presente a partir da repetição.

Na sessão que se seguiu, Amadeo trouxe novamente a dobradura de papel, mas dessa vez em uma folha amarela. Cortou novamente uma folha para que fizesse outra dobradura, como na sessão anterior. Ele mesmo foi dobrando junto com a sua folha já marcada, até que ficasse uma dobradura igual à de origem.

- O que é isso que ficou?

- Um peixe - disse Amadeo.

- Peixe? - perguntou a terapeuta com estranhamento. Não era o nome do lugar onde tu moravas antes?

- Peixe azul? - respondeu ele surpreso

- Isso.

- É o nome do abrigo onde eu morei antes - silêncio. Que saudades de lá. A gente ia para a aula bem cedo. No céu era noite ainda.

Silêncio.

- E porque tu saíste de lá?

- Porque me adotaram. Daí eu fui para onde estou agora.

Amadeo silenciou pensativo.

- Tem como pintar esse papel? - perguntou referindo-se ao peixe feito em folha amarela.

- Sim, podemos usar um giz.

Amadeo pegou um giz azul e pediu:

- Pinta para mim?

A terapeuta pintou de azul todo o papel amarelo que, novamente dobrado, vira um peixe azul. 
- Deixa que o contorno eu faço - afirma Amadeo. Ficou azul?

- Sim - respondeu a terapeuta. Ficou o teu Peixe Azul.

\section{Da Formação de Imagem ao Ato}

A cena analítica descrita trata-se de uma passagem importante do atendimento feito a uma criança que chega ao tratamento com pouco acesso às suas origens, a sua história de vida, tendo vivido durante grande parte dela em um abrigo; dado este trazido pelos pais sociais. No começo dos atendimentos, falava muito pouco e repetia várias vezes a mesma brincadeira, a saber, jogar a bola para terapeuta que a pedido dele, segurava uma cesta. Imediatamente a bola era devolvida para Amadeo que jogava novamente e assim sucessivamente ao longo de toda a sessão durante vários meses de atendimento.

É possível remeter essa primeira brincadeira de Amadeo ao Fort-Da trazido por Freud em "Além do princípio do prazer (1920)". Nessa passagem, Freud (1920) descreve a observação que fez de seu neto ao brincar de atirar para o alto um carretel de madeira enrolado em um cordão, de modo que caísse por cima do berço com cortina, onde o objeto desaparecia de sua visão, pronunciando o significativo "o-o-o-o", o qual se julgava não ser uma interjeição, mas ter o significado "fort", que em nota do tradutor brasileiro é traduzido como "foi-se"; "desapareceu", "foi embora". Posteriormente, a criança puxava-o para fora da cama, saudando-o com um alegre "da", traduzido como "aî", "está presente", "está aî", "está aqui". Esta era a brincadeira completa da criança: desaparecimento e retorno, que adquiriu sentido, de acordo Freud (1920), na medida em que se relacionava com a elaboração psíquica de renúncia à satisfação pulsional devido ao fato de sua mãe deixa-lo ali ao sair de casa.

Destaca-se com isso a importância do conceito de imagem nesse trabalho, uma vez que é a partir dela que podemos pensar as representações do sujeito advindas do inconsciente. Desse modo, nas sessões que se seguiram, Amadeo começara a entrar e sair da sala, desaparecendo do campo visual da terapeuta, para que essa começasse a buscá-lo até que conseguisse reencontrá-lo. Por fim, brincou de se esconder dentro da sala, pedindo que a terapeuta tapasse os olhos enquanto o fazia: "Fecha os olhos. Não pode ver. Deu! Pode me procurar".

Esse Fort-Da vivido em sessão, primeiro com a bola e a cesta e depois com o paciente e a terapeuta, possibilitou que se pensasse esse primeiro momento do atendimento como um lugar possível para formação de imagens de Amadeo. Imagens essas que pareciam não aparecer, deixando, por vezes, sensação de vazio naquela que o escutava até que a brincadeira de desaparece/aparece surgiu como uma brecha viável pare que essas imagens surgissem através do próprio corpo do paciente: "Onde será que Amadeo está? Será aqui? Não. Aqui? Achei!".

Dessa forma, o Fort-Da trazido na cena analítica se desdobrou no fenômeno do duplo, onde o reconhecimento da imagem de Amadeo se deu através do olhar do Outro. Sobre isso, França (1997) pontua a importância desse Outro no mundo-imagem, pois é através dele que o caminho do imaginário é possível para o sujeito.

O eu se estrutura na imagem dada a partir de um Outro, e é pela intervenção deste Outro, marcado por alteridade e duplicidade, que o Eu fascinado se conduz 
passivamente na trilha imaginária. Nesse caminho se reconhece onde não está. No fenômeno do duplo se explica a marca significante de duplicidade e alteridade que jamais desaparece e que pode a qualquer momento tomar forma e ser experimentada (...). Essa imagem irresistível, ligada a uma forma é uma representação inconsciente que reflete um desejo duplicado, que animará permanentemente nossas paixões (FRANÇA, 1997, p. 78).

Esse ensejo em que a imagem do sujeito é estruturada em meio ao desejo do Outro é destacado, pois a entrada no campo do imaginário se dá por essa via narcísica. No caso clínico em questão, Amadeo através do ato de pôr e repor o movimento permitiu que situasse a experiência de ausência e a significasse como ação criadora. Esse ato de criação implica formação de imagem por parte do sujeito, o que oferece subsídios para o trabalho clínico onde a via do imaginário ocupa lugar de importância e de possibilidade.

Sobre o Fort-Da e a sua aproximação com o ato criativo, Betts (2011) lembra Os Carretéis de Iberê Camargo como elemento-personagem da obra do artista. Esses objetos que sobravam do trabalho de costura da mãe e que Iberê brincava quando criança, foram reencontrados no fundo de uma gaveta por ele, sendo carregados de afetividade por remeterem a sua infância.

\begin{abstract}
O re-encontro imaginário com o objeto perdido das vivências alucinatórias de satisfação infantil, um dia ligadas a sua mãe, marcam na obra do artista a nostalgia de possíveis re-encontros metaforizados. $\mathrm{O}$ artista cria a partir do elemento carretel personagens que vivem, metaforizam e deslocam dramas da vida, dramas da vida que adquirem valor universal pois falam da condição humana (BETTS, 2011, p. 78, 79).
\end{abstract}

Nesse ato de criação de Iberê, costurado com a lembrança de seu vivido, é possível trazer à expressão aquilo que estava antecipado como inexpressível, ou seja, aquilo que era da ordem de processos que não tinham forma e remetiam ao vazio. A criação do artista, nesse sentido, visa preencher esse buraco, na esteira do que fez Iberê com seus carretéis, uma vez que "pode pintar emoções porque soube fazer outra coisa com carretéis de sua infância" (BETTS, 2011, p. 79).

René Passeron (2001a) assinala que no processo de criação do pintor o que ele sonha e pensa está amarrado aos seus fantasmas que empurram o artista à repetição. Diante disso, o ato criativo configura-se como uma "repetição libertadora do ato traumático antigo" (PASSERON, 2001a, p. 9), pois é esse ato traumático que convoca o artista ao vazio. Para o autor, "toda obra de arte é um curativo do vazio" (PASSERON, 2001a, p. 11), no qual esconde ao mesmo tempo em que trata, substituindo sua aparência perceptível a não aparência do ferimento sem, contudo, cicatriza-lo.

Sobre a questão do vazio, Regnault (2001, p. 16) coloca que "no princípio, está o furo. Depois, em torno do furo" para sublinhar a potência do vazio em meio ao ato criativo, na 
medida em que ele é o mote para gesto de criação. A obra de arte rememora o nada do qual se originou, apontando para ele e conferindo-lhe um valor essencial. Nesse sentido, na esteira do que Lacan (1959, p.155) postula acerca da arte, isto é, "Toda arte se caracteriza por um certo modo de organização desse vazio [...] De todo modo, o vazio permanece no centro", Regnault (2001, p. 22) aponta que "a arte, então, não se contenta em adornar, ilustrar; ela realmente organiza".

Dito isso, Regnault (2001) considera duas posições distintas e aparentemente incompatíveis colocadas por Lacan (1959): Em uma delas, o vazio representa a Coisa (das Ding), o que se aproxima da lógica do real. Outra posição seria a de que outra coisa representa a Coisa, colocando-a ao lado da representação e da arte. Essa segunda consideração acerca do vazio vai ao encontro do que se propõe nesse escrito, a saber, o ato criativo enquanto movimento da arte no tocante às questões do sujeito, no qual a psicanálise se ocupa. Sobre essa aproximação desses dois campos, Regnault (2001, p. 20) acrescenta "porquanto o artista preceda o psicólogo, sua arte deve fazer avançar a teoria psicanalítica”.

A respeito desse vazio constituinte do sujeito que encontra na arte e na psicanálise possibilidades de renovação desde um outro lugar de enunciação, o fragmento clínico trazido vem a ratificar esses atos como o advento do novo. A cena em que Amadeo traz em suas mãos a dobradura feita de casa vai ao encontro desse novo que se apresenta diante do ato criativo, tendo em vista que as marcas feitas no papel remetem às marcas vividas por Amadeo que já estavam no registro de seu corpo, mas que puderam emergir diante do seu ato. A dobra, portanto, como um movimento de fazer inscrição no corpo da imagem. Desse modo, aquilo que silenciosamente se repetia incessantemente nas sessões através do Fort-Da e que aludia ao dentro/fora, pode ganhar contornos e fala.

$\mathrm{O}$ ato analítico e o ato artístico revelam um contorno do objeto e do sujeito que se revela, no qual a obra faria função de um testemunho de uma nova atitude ante a vida. Os produtos artísticos trazem consigo "traços da história que lhes deu origem e a pulsão de pensar armazenada nas formas visíveis" (SOUSA, 2012, p.89), à exemplo do peixe de papel como a Obra de Amadeo, por ser carregado de pulsão, marcas, afeto e sentido que dizem de suas vivências. $\mathrm{O}$ ato artístico produzido em sessão encontrou no peixe de papel seu ponto analítico ao ser nomeado "Peixe Azul", significante fundamental no ensejo desse caso clínico.

$\mathrm{O}$ ato criativo possibilita um novo lugar de enunciação do sujeito, uma vez que propõe uma ruptura do mesmo, da repetição. Desse modo, é tocante ao ato analítico em que os produtos são novos significantes decorrentes do deslizamento da cadeia significante. Ao 
sujeito é possível desejar e fazer algo novo com esses significantes abertos à polissemia. Betts (2011) afirma como possibilidade do ato psicanalítico a reposição do sujeito frente à vida, bem como a qualidade criativa da mesma. Afinal, do que diz o ato analítico, em sua gênese, senão de um ato criativo?

A obra de Amadeo deu vazão à possibilidade da criação de algo novo em sua vida; algo que rompesse a repetição que se aproximava ao vazio sem representação possível. Quando esse vazio encontra o ato de criação, torna-se passível de interpretação por parte daquela que o escuta e há a emersão de um outro lugar de enunciação desde seu Peixe Azul. O produto desse ato, contudo, não foi seu Peixe Azul mas todo o processo de criação que viabilizou que suas representações ganhassem forma. Sobre isso, Passeron (2001b) coloca que a criação está para além da expressão, pois se refere a tornar real um objeto que cria vida independente e, estando fora do sujeito, manifesta-se por meio dele.

A aproximação do fazer artístico com o a clínica da psicanálise pode ser pensada na mesma direção que a cena vivia por Amadeo propõe, em que o processo de criação do Peixe falava dele enquanto sujeito, na medida em que suas representações encontravam possibilidades de serem representadas. Como coloca Kon (2001), o parentesco entre a atividade artística e a clínica psicanalítica reside em "um fazer que se dá no ato da feitura" (KON, 2001, p. 45). Em meio a isso, o que entra em cena são processos inconscientes através das pulsões, das formações de imagem, das associações.

O gesto de criar coloca em cena pulsões oriundas do psiquismo do sujeito que acharam via de se representar através desse ato. Passeron (2001b, p. 69) acrescenta que "a criação implica uma mobilização sintética das pulsões reprimidas", o que coloca a poiética em relação com a patologia, uma vez que aquela acrescenta novos determinantes dessa, seja para alargar ou reduzir seu campo. A poiética é entendida na direção que o autor a coloca, a saber, não somente como a ciência dos processos instauradores, mas como uma ética da criação, como uma reflexão do que está em obra na obra sendo feita, o que figura-se como oposição aos demais estudos que privilegiam o produto final.

Sobre isso, Frayze-Pereira (2005) acrescenta que o fato de colocar em questão os fundamentos da obra, independente do momento em que ela se encontra, requer a valorização do fazer artístico, de uma práxis da instauração criadora. Desse modo, o que está em evidência através das formas criadas, na obra em questão o peixe de papel; dos materiais utilizados; folha em branco, folha amarela e giz de cera azul; é a essência da obra: as suas origens que impulsionaram o artista à sua criação. Esse entendimento coloca a arte em 
consonância com a psicanálise em que o que está em questão é "o delicado problema da manifestação de um dizer sempre fugido, sempre aquém de uma plena realização" (FRAYZE-PEREIRA, 2005, p. 39).

A prática clínica implica em uma escuta que abarque questões singulares do sujeito que fala através do seu sintoma daquilo que, por vezes, não tem forma e, para tanto, se repete. O fazer do psicanalista diz de uma ética que possibilita dar contornos àquilo que carece de representação, que antecede à palavra. O fazer artístico se aproxima disso na medida em que traz ao mundo algo de que, sem o ato de criação, seria da ordem do irrealizado. Como bem coloca Frayze-Pereira (2005):

Considerando que é próprio do artista pôr no mundo um ser que jamais foi visto, nunca foi ouvido ou tocado antes dessa instauração, pensar esteticamente supõe fazer contato com esse campo de passagem entre o não-ser artístico e a forma perceptível, assim como pensar psicanaliticamente implica transitar entre o não-dito e o dizível (...) Fundamental, desde a dinâmica da presença e da ausência do sensível, a experiência estética é vizinha da experiência psicanalítica: uma silenciosa abertura ao que não é nós e que em nós se faz dizer (FRAYZE-PEREIRA, 2005, p. 38).

A respeito dessa passagem, é importante destacar a função de algo que fala ao sujeito para além de todo dizível, ou seja, daquilo que é não-dito, não-visível, mas que escapa aos poros e faz função, seja como criação artística, seja como sintoma. Esse movimento pulsional que Freud (1915a) situa como uma força constante impele o sujeito à ação, uma vez que "as ações de fuga não conseguem eliminá-la, ela é irremovível” (FREUD, 1915b, p. 147). Aponta-se assim para o ato criativo como uma via possível de representação em que a formação de imagem encontra estreita relação com esse processo inconsciente, uma vez que o termo "Vorstellung" traduzido por representação também remonta à "Imaginação" na medida em que também foi utilizado na acepção de "imagem interna".

As imagens que Amadeo pode trazer para cena clínica, a exemplo do seu Peixe Azul reportam às suas representações que, embora em um primeiro momento pudessem remeter a um silêncio infindável que parecia tocar o vazio, o permitiu falar desde um outro lugar de enunciação. É justamente naquilo que parecia não lhe dizer que Amadeo pode revelar suas marcas e com isso falar-se. Esse ato criativo que se encontrou com o ato analítico na medida em que essa passagem foi vivida em um lugar de transferência no qual o olhar da terapeuta fez função, implicou no advento do sujeito como objeto causa do desejo.

Relativo ao ato e sua estreita relação com o inconsciente, sublinha-se que "o ato vem a desequilibrar as imagens que construímos para dar conta deste fora de lugar que é o 
inconsciente" (SOUSA, 2012, p.85). Nesse sentido, Freud (1912) acrescenta que "todo ato psíquico começa com um ato inconsciente" (FREUD, 1912, p. 87), na medida em que o inconsciente é o lugar em que os processos que constituem a vida psíquica ocorrem, sendo, portanto, inevitável ao sujeito. Com isso, é retomado um aspecto acerca do inconsciente que vai ao encontro das considerações desse escrito, isto é, o ato criativo proveniente de processos psíquicos que encontraram vias de representação através de um fazer artístico.

Freud (1915b) coloca que o núcleo do inconsciente é composto de representante pulsionais que desejam escoar. Para tanto, é necessário que consigam aderir a uma ideia (Vorstellung) ou que se manifestem por um estado afetivo; do contrário, nada se saberia sobre a pulsão. $\mathrm{O}$ ato criativo de Amadeo oferece um olhar frente aos seus processos inconscientes que estiveram mobilizados no seu fazer criativo, podendo culminar na forma de um peixe de papel e convocar-lhe à palavra.

Relativo à forma encontrada que fala de todo o ato do sujeito, sem com isso restringir seu fazer a esse produto final, o processo artístico em meio à ideia, ao projeto e à realização da obra passa invariavelmente por uma experiência informe, no sentido de transição de uma forma à outra. Com efeito, esse informe remete a uma passagem essencial na apreensão do fazer artístico e "é aqui que encontramos o ato como produtor de novas formas" (SOUSA, 2012, p.88). Assim sendo, os atos que se tornam formas buscam trazer ao visível todo o processo de produção que culminou na obra, sem com isso, deixar de lado todo traçado de sua origem. É nessa possibilidade de se dar formas ao informe, produzindo com isso obras de arte, que os atos podem ser efetivamente criativos. Nesse sentido, as formas essenciais produzidas por esse ato, permitem um deslocamento na posição de sujeito como efeito de linguagem, conforme mostra a cena clínica vivida por Amadeo.

\section{Do Ato Criativo ao Estranhamento da Criação}

$\mathrm{O}$ ato criativo fala de algo produzido por aquilo que afeta o sujeito. Esse afetamento é entendido com estreita relação ao conceito de pulsão proposto por Freud (1915a), na medida em que compõe ao lado do representante pulsional, destinos diferentes para o recalque. A designação de quantidade de afeto é correspondente à pulsão "na medida em que se desprendeu da representação e encontra expressão, de acordo com sua magnitude, em processos que se fazem perceber à sensação na forma de afetos" (FREUD, 1915a, p. 182). O termo affekte "afetos" é descrito em nota do tradutor brasileiro que, embora seja utilizado na 
acepção de "energia que ao se expressar na consciência adquire um qualidade", sendo esta última ligada à irrupção de medo, angústia; é remetido ao alemão que evoca a idéia de excesso, de "descontrole das emoções que transbordam” (FREUD, 1915a, p. 186).

É justamente a esse transbordamento que o ato de criação remonta na produção do artista. Derdyk (2001) conjuga essa mobilização de emoções que afetam o sujeito ao cultural quando destaca que o ato criador mescla esses campos de força para a construção de uma forma inaugural. A experiência de criação dessa forma coloca em jogo "forças originárias embutidas e ocultas, latejando pulsações que emergem de repertórios pertinentes ao universo do observável, da memória e do imaginário" (DERDYK, 2001, p. 15). Esse entendimento do que é oriundo ao inconsciente no processo de criação do artista vai em direção ao que Lacan (1967) propõe quando aproxima o ato criativo ao ato analítico, no sentido de que ambos apontam para práticas em que o sujeito é posto em questão.

Tanto o ato criativo quanto o ato analítico promovem uma descontinuidade na construção do sujeito, indicando um movimento de ultrapassagem. Apontam para uma divisão subjetiva, no qual estão em jogo ambivalências, paradoxos, oposições; dualidades próprias do funcionamento inconsciente como aponta Freud (1915b). Não há nesse sistema, portanto, lugar para a negação, dúvida e diferentes graus de certeza. Os atos analítico e criativo "fazem resistência à inércia que alimenta os ideais de completude" (SOUSA, 2012, p. 91), trazendo à cena a experiência do vazio, constitutiva e necessária.

$\mathrm{O}$ ato criativo adquire necessariamente uma potência crítica, desequilibrando saberes vigentes: "Criar é abrir descontinuidades, interrupções do fluxo do mesmo" (SOUSA, 2007, p.19). A obra criada produz novas significações, pois com ela advém a capacidade de se imaginar novas imagens para além daquelas já existentes e por vezes engessadas, que convocam o sujeito ao automatismo. Conte (2001) acrescenta que o gesto de criação promove uma ruptura do já estabelecido quando coloca que "todo ato criativo implica produção de um conteúdo que rompe com um continente" (CONTE, 2001, p.153), provocando a aproximação de uma verdade até então não revelada.

Nesse sentido, uma articulação do ato criativo como um ato utópico é proposta, pois a utopia remonta a uma experiência de um fazer, experiência essa poïética, pois tal como o gesto da criação, a utopia não pode ser dita antes da ação. Ela é pensada dentro da idéia do inacabado, onde a invenção e a reinvenção ocupam lugar de excelência. Essa aproximação entre arte e utopia é trazida por Jimenez (2003, apud SOUSA, 2007, p. 33) quando coloca que 
"toda obra de arte teve e ainda tem uma janela utópica por onde podemos ver uma paisagem no processo de constituição".

A utopia refere-se a um território de crise em que é possibilitada uma fratura do presente. Trata daquilo que fracassa; do que gagueja na repetição das formas constituídas, encontrando justamente nesse fracasso o ponto essencial para abertura ao desconhecido. Desse modo, o discurso utópico dá lugar a novas posições enunciativas, pois aponta a insuficiência do presente em responder ao desejo do sujeito. Nesse ensejo, a utopia sublinha a potência dos espaços de criação, uma vez que estes possibilitam através de seu fazer o direito à recusa do já instituído.

Ato criativo e ato utópico acabam por se encontrar na medida em que ambos colocam em cena um desejo. Nesse sentido, a utopia é pensada como formação do inconsciente, onde a exemplo do gesto de criação, algo da ordem do inapreensível, do incomensurável entra em jogo, produzindo intervalos e suspensões. Acaso, a Obra de Amadeo, advinda por meio de seu ato criativo não poderia ser pensada como uma criação utópica?

A potência do ato é sublinhada na medida em que ele estabelece um corte e com isso inaugura um antes e um depois. Diz, portanto, de uma ruptura na repetição; de um furo possível capaz de produzir novas imagens e novas formas, lançando-se ao desconhecido. A Obra Peixe Azul de Amadeo convoca a olhar sobre seu ato criativo através da lente da repetição, visto que no primeiro momento de sua criação vários peixes foram repetidamente criados ao longo de toda a sessão até que posteriormente se chegasse ao Peixe Azul e igualmente sob a ótica do duplo, tendo em vista que a figura do outro ocupou lugar fundamental nesse ato.

Nessa direção, a cena clínica que trazida nesse escrito serve como uma imagem em que o fenômeno do estranho, proposto por Freud apareça como ponto de estofo. Em Das Unheimlich (1919) Freud coloca alguns dos paradoxos existentes na repetição, a saber, conhecido/desconhecido, familiar/estrangeiro, onde a fronteira aparece como indeterminada. Assim sendo, na compulsão à repetição, prevalente sobre o princípio do prazer, há sempre algo percebido como estranho. Ao analista cabe fazer cargo disso que repete no sujeito e que recaí por vezes no fracasso, interrogando-o justamente nesse equívoco para que o paciente possa se escutar.

O estranho, portanto, sutura aquilo que parece fora ao sujeito como estrangeiro a ele, ao que lhe é mais íntimo. Freud considera acerca desse tema que "em geral, somos lembrados de que a palavra 'heimlich' não deixa de ser ambígua, mas pertencente a dois conjuntos de 
idéias que, sem serem contraditórias, ainda assim são muito diferentes: por um lado significa o que é familiar e agradável e, por outro, o que está oculto e se mantém fora de vista" (FREUD, 1919, p. 242, 243). Nesse sentido, conhecido e desconhecido se mostram como avessos que no final acabam por se coincidir.

Sobre o ato criativo de Amadeo, sublinha-se especialmente a designação que Freud (1919, p. 240) atribui à heimlich como "pertencente à casa ou à família". A conjuntura clínica em que o ato incidiu se constituía em torno da história de vida até então não contada pelo paciente. Suas origens, sua filiação, seu nome e sobrenome não apareciam na fala daquele sujeito e, no entanto, puderam se precipitar naquele ato de criação.

Aquilo que havia de mais familiar a Amadeo, lhe fazia questão para além da demanda que o trouxera inicialmente para o tratamento, qual seja, seus problemas de fala e posteriormente de aprendizagem. Não foi à toa que aquela forma de papel encontrada ao final de sua produção causou surpresa e estranhamento ao ser nomeada de "Peixe Azul" e reportada imediatamente ao nome do abrigo de onde viera. Aproxima-se assim de outra denominação possível à heimlich proposta por Freud (1919, p. 241), a saber, "escondido, oculto da vista de modo que os outros não consigam saber". Nesse sentido, a Obra Peixe Azul circunscreve um território em que se abre um lugar para um nome próprio.

O fenômeno do estranho vai ao encontro dos desdobramentos produzidos no caso clínico em questão, ou seja, de processos puramente inconscientes onde elementos analíticos importantes entram na composição dessa cena. Portanto, aquilo que causou estranhamento foi encontrado em coisas que há muito tempo eram familiares ao sujeito; familiares no sentido de algo íntimo a ele e que desse modo, puderam mobilizá-lo à criação. A obra produzida em sessão, advinda em meio à transferência, lançou a possibilidade de se criar um fora que desorganizasse o que estava dentro, convocando o sujeito à representação.

Freud (1919) postula que no tema da estranheza se destaca o fenômeno do duplo que aparece em todas as formas e graus de desenvolvimento do sujeito, remetendo ao narcisismo primário. "Quando tudo está dito e feito, a qualidade de estranheza só pode advir do fato de o duplo ser uma criação que data de um estádio mental muito primitivo, há muito superado" (FREUD, 1919, p. 254). O narcisismo primário implica em um modo de investimento na relação com o outro em que uma imagem de unidade é introduzida sob um estatuto de engano e de aparência, onde a idéia de miragem demanda constante reconhecimento (FRANÇA, 1997, p. 72). O duplo, nessa direção, é pensado como uma "metáfora da repetição de si 
mesmo" (Sousa, 2001, p. 132), em que a sensação de desamparo é experimentada em meio à repetição, colocando esse encontro, por vezes, como insuportável.

Betts (2006, p.16) coloca que a imagem produzida no ato de criação do artista se desdobra em dois aspectos, "nos quais se conjugam a imagem que fascina e o significante que interroga". À imagem, há a possibilidade de fascinar pela beleza em que o eu familiar de quem olha é refletido e pelo horror com que o eu se vê privado do reflexo de sua identidade. Assim, o unheimlich é inscrito na obra sob a forma de presença/ausência que "interrogam o observador, convocando-o a responder de um lugar estranho à familiaridade do eu" (BETTS, 2006, p.16).

$\mathrm{O}$ ato criativo de Amadeo convocou aquela que o escutava e o olhava durante a cena analítica a observar o tempo de falar e o tempo de calar diante o seu processo de criação. Com isso, o inconsciente encontrou lugar de abertura e fechamento, trazendo à tona seus processos mais genuínos de representação. A sua Obra trouxe consigo a inquietação do unheimlich no momento em que a incidência da palavra operou em meio à produção daquele sujeito. Como coloca Frayze-Pereira (2005)

(...) esquecendo-se de si para deixar-se surpreender, o espectador perceberá surgirem na obra interrogações que se colocarão a ele mesmo como seu destinatário. E antes de falar por sua própria conta, será preciso que o espectador-analista empreste sua própria voz a essa estranha potência que o interpela, respeitando a Psicanálise e, sem redução ou idealização, a desnorteante força a Arte (FRAYZEPEREIRA, 2005, p.91).

O estranho fenômeno da criação de Amadeo o possibilitou criar um novo lugar de enunciação, fazendo algo do seu desejo emergir através de sua Obra. O material inconsciente irrompeu as barreiras que lhe foi imposta pelo processo do recalque, trazendo com ele a criatura. Criatura enquanto produto do criador; mas que coloca o acento sobre o sujeito da criação, como coloca PAZ (1982, apud Derdyk, 2001, p. 17) "o ato de descobrir entranha a criação do que vai ser descoberto: nosso próprio ser". Amadeo foi nomeado de artista e, sobretudo, de criador; verbo no infinitivo que aponta para a potência do que pode vir a ser.

Acrescenta-se a isso:

$\mathrm{O}$ ato criativo e o ato psicanalítico operam como a mão de um escultor do tempo, produzindo interrupções que possibilitem novas leituras de vida, novos caminhos, novos sentidos. Estas produções evidenciam uma interrogação sobre a origem e desvelam nossa desarmonia constitutiva. É por esta razão que toda obra de arte nos dá a possibilidade reflexiva de também chegar mais perto da ficção que nos constitui como sujeitos (SOUSA, 2001, p. 132). 
$\mathrm{Na}$ cena vivida por Amadeo sob o olhar da terapeuta, é possível pensar o ato criativo como a banda de Moebius, onde dentro e fora não são separados. $\mathrm{O}$ avesso e direito estão do mesmo lado e a passagem do interior para exterior é contínua. Desse modo, o ato criativo toca $\mathrm{o}$ ato analítico, tendo em vista esse funcionamento que coloca em cena a repetição e a falta e, com isso, o sujeito.

\title{
FOLDS OF AN ORIGIN: CLINICS, CREATION AND UTOPIA
}

\begin{abstract}
This article is a written on the creative act and its deployments in what concerns to psychoanalytic clinic. The dialogue between arts and psychoanalysis shows strength once both fields are close at the same time they are strange to each other, causing doubts and reflections that culminate in the possibility of creation of new forms, new paths. We begin from a clinical scene in which the gesture of creation meets analytical possibility as this act occurs in the context of transference, when the look from the other occupies an essential spot. The reflection on the clinical case aims to deepen axes of reflection such as image formation, the interfaces between the significant and the unconscious and analytical act and utopia.
\end{abstract}

Keywords: Creative act. Psychoanalysis. Utopia.

\section{PLIEGUES DE UN ORIGEN: CLÍNICA, CREACIÓN Y UTOPÍA}

\section{Resumèn}

Este trabajo es una escritura acerca del acto creativo y sus despliegues en relación a la clínica psicoanalítica. El diálogo entre el arte y el psicoanálisis mostrase potente en la medida en la cual eses campos se acercan del mismo modo que se extrañan, causando dudas y reflexiones que culminan en la posibilidad de creación de nuevas formas, nuevos caminos. Partimos de una escena clínica donde el gesto de creación encuentra posibilidad analítica puesto que el acto es vivido en el contexto de la transferencia, donde la mirada del otro ocupa un lugar esencial. La reflexión acerca del caso clínico busca profundizar ejes de reflexión como la formación del imagen, las interfaces entre significante e inconsciente y acto analítico y utopía.

Palabras-Claves: Acto Creativo. Psicoanálisis. Utopía. 


\section{Referências}

BETTS, Jaime. Ato analítico, ato religioso e ato de criação artística. Correio da APPOA, Porto Alegre, n. 149, p. 13-16, ago. 2006.

BETTS, Jaime. Carretéis de Iberê, fort-da de Freud. Ato Psicanalítico - Ato de Criação. Correio da APPOA, Porto Alegre, n. 208, p 77-81, dez.2011.

CONTE, Júlio. O silêncio dos espaços infinitos. In Sousa, E.L.A., Tessler, E., Slavutzky, A. (Org). A invenção da Vida: arte e psicanálise. Porto Alegre: Artes e Ofícios, 2001. p. 150154.

DELEUZE, Gilles. A dobra-Leibniz e o Barroco. Campinas: Papirus Editora, 1991. p. 58.

DERDYK, Edith. Ponto de chegada, ponto de partida. In Sousa, E.L.A., Tessler, E., Slavutzky, A. (Org). A invenção da Vida: arte e psicanálise. Porto Alegre: Artes e Ofícios, 2001. p. 14-21.

FRANÇA, Maria Inês. Psicanálise, estética e ética do desejo. São Paulo: Perspectiva, 1997.

FRAYZE-PEREIRA, João A. Arte, dor: inquietudes entre Estética e Psicanálise. São Paulo: Ateliê Editorial, 2005.

FREUD, Sigmund. Além do Princípio do Prazer (1920) in: Escritos Psicológicos do Inconsciente. Rio de Janeiro: Imago, 2006. p. 123-198, v. 2. O inconsciente $(1915 b)$ in: Rio de Janeiro: Imago, 2006. p. 13-74, v. 2. . Escritos Psicológicos do Inconsciente. 2006. p. 233-273. v. 17. O estranho (1919) in Obras Completas. Rio de Janeiro: Imago, Pulsões e destinos da pulsão (1915a) in Inconsciente. Rio de Janeiro: Imago, 2004. p. 133-173. v. 1.

KON, Noemi Moritz. Entre a psicanálise e a arte. In Sousa, E.L.A., Tessler, E., Slavutzky, A. (Org). A invenção da Vida: arte e psicanálise. Porto Alegre: Artes e Ofícios, 2001. p. 39-49.

LACAN, Jacques. A Ética da Psicanálise (1959) in O Seminário, livro VII. Rio de Janeiro: Jorge Zahar, 1988.

PASSERON, René. Por uma Poïanálise. In Sousa, E.L.A., Tessler, E., Slavutzky, A. (Org). A invenção da Vida: arte e psicanálise. Porto Alegre: Artes e Ofícios, 2001a. p. 9-13.

Poḯtica e patologia. In Sousa, E.L.A., Tessler, E., Slavutzky, A. (Org). A invenção da Vida: arte e psicanálise. Porto Alegre: Artes e Ofícios, 2001b. p. 57-72.

REGNAULT, François. Em torno do Vazio. A arte à luz da Psicanálise. Rio de Janeiro: Contra Capa Livraria, 2001.

SOUSA, Edson Luiz André. Quando atos se tornam formas. Correio da APPOA, Porto Alegre, n. 213, p. 85-94, jun. 2012. 
Uma estética negativa em Freud. In Tessler, E., Slavutzky, A. (Org). A invenção da Vida: arte e psicanálise. Porto Alegre: Artes e Ofícios, 2001. p. 125-133.

Uma invenção da utopia. São Paulo: Lumme Editor, 2007.

Data de recebimento: $12 / 05 / 14$

Data de aceite: 26/08/15

\section{Sobre os autores:}

Ariane Santellano de Freitas é formada em Psicologia pela Universidade Federal de Santa Maria. Possui Especialização em Atendimento Clínico com Ênfase em Psicanálise pela UFRGS. Endereço eletrônico: afsantellano@ hotmail.com

Luiz André de Sousa é Psicanalista, Professor do PPG Psicanálise: Clinica e Cultura, Professor do PPG Psicologia Social e Institucional e PPG Artes Visuais - Universidade Federal do Rio Grande do Sul. Pesquisador do CNPQ. Endereço eletrônico: edsonlasousa@uol.com.br 